\title{
LA APLICACIÓN DE LA DOCTRINA DE LA PÉRDIDA DE OPORTUNIDAD Y EL DAÑO MORAL COMO CONCEPTO INDEMNIZABLE
}

\author{
LETICIA LATORRE LUNA
}

Abogada y doctoranda

Universidad de Murcia

leticia.latorrel@um.es

STS DE LA SALA 5. a DE 20 DE MARZO DE 2018

N. ${ }^{\circ}$ SENTENCIA: 462/2018. N. ${ }^{\circ}$ RECURSO: $2820 / 2016$

CENDOJ: (ROJ: STS 1096/2018 - ECLI:ES:TS:2018:1096)

VOCES: Responsabilidad patrimonial, Administración Pública, funcionamiento normal o anormal, servicios públicos, indemnización, asistencia sanitaria, pérdida de oportunidad, doctrina, lex artis.

El Alto Tribunal se pronuncia respecto a la responsabilidad patrimonial por defectuosa conducta asistencial y acerca de los límites de aplicación de la doctrina de la pérdida de oportunidad cuando concurre la existencia de de infracción de la "lex artis" reconocida por la propia sentencia de instancia, recordando que la teoría de la pérdida de oportunidad se configurara como una cierta pérdida de una alternativa de tratamiento, pérdida que se asemeja en cierto modo al daño moral y que es el concepto indemnizable.

La sentencia objeto de análisis, dictada por la sección quinta de la Sala de lo Contencioso-Administrativo del Tribunal Supremo, en fecha 20 de marzo de 2018, desestima íntegramente el recurso de casación interpuesto contra la sentencia de fecha 20 de julio de 2016 dictada por la Sección Segunda de la Sala de lo Contencioso Administrativo del Tribunal Superior de Justicia de la Comunidad de Valencia, donde se estima parcialmente el recurso interpuesto por una paciente con patología cerebral contra la impugnación la desestimación de la desestimación contra la Administración por defectuosa conducta asistencial sanitaria.

En concreto, la actora versa su recurso en la concurrencia de mala praxis debido al retraso de diagnostico injustificado en la patología cerebral que presentaba, lo que conllevó posteriormente a la aplicación de un tratamiento inadecuado, añadiendo la falta de información médica sobre la realización de biopsia endoscópica, valorando las secuelas ligadas al proceso patológico por la cantidad total de $838.866,72 €$, reclamando las mismas en concepto de 
indemnización a la Administración Pública por responsabilidad patrimonial en base a la asistencia sanitaria. De contrario, la administración demandada, considera que en todo momento la actuación médica sanitaria fue conforme a la lex artis ad hoc, tanto en el retraso del diagnostico imputado como a la falta de información. Por otro lado, la compañía de seguros codemandada niega la existencia de nexo causal entre la asistencia prestada a la paciente y las lesiones reclamadas.

Finalmente, en la sentencia dictada en primera instancia, la Sala juzgadora estima que cabe responsabilidad patrimonial de la Administración debido a que la asistencia sanitaria proporcionada en neurología no se realizó conforme a las exigencias propias de los síntomas presentados, no llegándose por tanto a profundizar en un estudio de la paciente en los términos requeridos. De igual modo, el órgano juzgador entiende que consta acreditado que la prueba de biopsia practicada no fuera precisa, a pesar de ser el motivo principal de la mayoría de las secuelas de la paciente, por todo ello, reconoce a la paciente el derecho de ser resarcida por parte de la Administración en concepto de responsabilidad patrimonial, cuantificando la indemnización a percibir por importe total de 40.000,00 €, valoración cuantificada con arreglo a los criterios establecidos por el art. 141 de la Ley 30/92.

Ante dicha resolución, el Alto Tribunal, en la sentencia objeto de análisis, entiende que la Sala de instancia ha fijado la citada cuantía exigible a la Administración en concepto de responsabilidad patrimonial empleando la doctrina de la pérdida de oportunidad, doctrina que según la parte recurrente considera que ha sido indebidamente aplicada, puesto que la propia sentencia reconoce la existencia de una infracción de la "lex artis", siendo en todo caso, la doctrina de la pérdida de oportunidad una figura que se ha de aplicar de manera alternativa por inexistencia de infracción de la "lex artis".

A pesar de que en la sentencia objeto de comentario, la sección quinta de la Sala Contencioso-Administrativo del Tribunal Supremo reconoce que la doctrina de la pérdida de oportunidad constituye una figura que ha de aplicarse como alternativa a la quiebra de la "lex artis", añade que cabe la aplicación de la citada doctrina de la pérdida de oportunidad aún en los casos en los que exista infracción de la "lex artis", puesto que misma permite el derecho a ser resarcido por daños y perjuicios y, por consiguiente dar una respuesta indemnizatoria aún sin existir una quiebra de la "lex artis", en concepto de daño producido por el incorrecto funcionamiento del servicio sanitario. De igual modo, el Alto Tribunal nos recuerda que cabe la responsabilidad en el ámbito de la sanidad pública, no únicamente por un defectuoso funcionamiento del servicio, sino también cuando se genera un riesgo o irrogación de un sacrificio especial.

En definitiva, lo que se cuestiona en la sentencia objeto de análisis es si cabe la aplicación de la doctrina de la pérdida de oportunidad aún existiendo acredita la infracción de la "lex artis", teniéndose en cuenta que la jurisprudencia asentada sobre la citada doctrina es distinta a la referente a la "lex artis", puesto que la "pérdida de oportunidad" hace referencia a la incertidumbre sobre una omisión de actuación médica, es decir, en la perdida de oportunidad lo que se da es una falta de actuación, que en caso de haber existido se hubiera evitado o mejorado el deficiente estado de salud del paciente. Así pues, a la hora de concretar la indemnización en el caso de la doctrina de la pérdida de oportunidad, se han de tener en cuenta dos elementos fundamentales, por un lado, si la actuación médica hubiera sido finalmente beneficiosa y, por otro lado, la entidad o alcance de ese efecto beneficioso. Por ello, entiende el Alto Tribunal que en el caso objeto de litigio, lo que genera a la paciente el derecho a ser resarcida por daños y perjuicios, se debe al retraso de 18 y 20 minutos en avistar enfermería al ginecólogo de guardia y al anestesista, no siendo este hecho, por tanto, un quebrantamiento propio de la "lex artis" por 
mala praxis, sino una falta de actuación por el servicio sanitario, esto es, una pérdida de oportunidad.

Debido al anterior planteamiento, el Alto Tribunal se cuestiona si la pérdida de oportunidad conlleva implícita una actuación por mala praxis. De conformidad a la jurisprudencia asentada sobre esta materia, se concreta que lo que se da en la pérdida de oportunidad es una pérdida a una alternativa de tratamiento, lo que ocasionaría, más que un daño físico propio de la mala praxis, un daño moral, que sería el concepto indemnizable. Por consiguiente, en la pérdida de oportunidad lo que nos encontramos no es propiamente una demora en el diagnóstico, sino un retraso en el tratamiento en sí. Así pues, la cuantía de la indemnización dependerá del grado de probabilidad que se estime concurrente en cada caso, sin llegar a ser posible en ningún caso, la reparación integral del daño, precisamente por el hecho de que con la pérdida de oportunidad el daño indemnizable es el moral.

Asimismo, en la citada sentencia, la Sala Contencioso-Administrativa del Tribunal Supremo entiende que a pesar de que siempre sea objeto de indemnización el daño causado al estado de salud del paciente, en el caso de la doctrina de la pérdida de oportunidad la indemnización es en concepto al daño moral, por ello siempre es parcial, debido a la falta de probabilidad suficiente que acredita el nexo causal entre la omisión o falta de acción por parte del facultativo medico y las secuelas sufridas por el paciente. Por ello, estima pertinente reducir la indemnización que fija la Sala de instancia por el importe de 220.000 euros a la cantidad de 110.000 euros, debido a que no consta acreditado el elevado "grado de probabilidad de que la actuación médica omitida hubiera producido un efecto beneficioso en el estado final del paciente, ni tampoco el grado, entidad o alcance de este hipotético efecto favorable."

En concreto, como se puede apreciar en la citada sentencia de fecha 20 de marzo de 2018, la teoría de la pérdida de oportunidad viene a configurarse como una cierta pérdida de una alternativa de tratamiento (no del diagnostico) pérdida que se asemeja en cierto modo al daño moral, siendo por tanto, éste el concepto indemnizable. Así pues, cabe la posibilidad de afirmar que lo que genera en el paciente el derecho a ser resarcido es la actuación médica que priva al paciente de determinadas expectativas de curación, pero siendo reducida la totalidad de la indemnización computada según los daños ocasionados en la salud del paciente, debido a la probabilidad de que el daño se hubiera producido, igualmente, de haberse actuado diligentemente.

Por consiguiente, nos encontramos ante supuestos de estricta incertidumbre causal, dando como resultado tras la aplicación de la citada doctrina a dos resultados distintos según sea el grado de probabilidad. Así pues, cuando el grado de probabilidad es elevado (a partir del $80 \%$ ) se viene a convertir en razonable certeza (límite positivo), sin embargo, cuando el grado de probabilidad es inferior al $20 \%$, nos encontramos ante una probabilidad nula (límite negativo), ubicándose la pérdida de oportunidad en el punto medio entre ambos extremos, negativo y positivo. De igual modo, se ha de tener presente que a efectos de delimitar cada caso no solamente se tiene en cuenta los grados de probabilidad, sino también otros factores, como las patologías previas de los pacientes, así como el hecho de que no exista ni siquiera una mínima probabilidad o una cierta incertidumbre de que, aunque no se hubiera producido el retraso, error de diagnóstico o demora en el diagnóstico, el resultado hubiera sido el mismo.

En conclusión, la aplicación de la doctrina de la pérdida de oportunidad nos conduce a diversas dificultades y riesgos en su delimitación, produciéndose sobre todo riesgos en una excesiva aplicación por parte de los órganos jurisdiccionales tanto en aquellos supuestos de alta probabilidad, que podrían dar lugar a mala praxis, con reparación íntegra del daño, como en 
aquellos supuestos en los que existe escasa probabilidad de haber obtenido un resultado distinto más favorable para la salud, que no dan lugar a indemnización. Debido a lo anterior, resulta necesario establecer límites, grados y criterios a fin de determinar cuando realmente nos encontramos ante un supuesto de hecho propio de pérdida de oportunidad. 